Article

\title{
Lipid-Based Formulations Containing Labrafil M2125-CS: A Deep Investigation on Nanosystem Stability
}

\author{
Martine Tarsitano $^{1}\left(\mathbb{D}\right.$, Maria Chiara Cristiano ${ }^{2, *(D)}$, Antonia Mancuso ${ }^{2} \mathbb{D}$, Antonella Barone $2 \mathbb{D}$, Daniele Torella ${ }^{2}$ \\ and Donatella Paolino ${ }^{2}$ (D) \\ 1 Department of Health Sciences, University of Catanzaro "Magna Graecia", 88100 Catanzaro, Italy; \\ martine.tarsitano@studenti.unicz.it \\ 2 Department of Experimental and Clinical Medicine, University “Magna Græcia” of Catanzaro, \\ 88100 Catanzaro, Italy; antonia.mancuso@unicz.it (A.M.); barone@unicz.it (A.B.); dtorella@unicz.it (D.T.); \\ paolino@unicz.it (D.P.) \\ * Correspondence: mchiara.cristiano@unicz.it
}

check for

updates

Citation: Tarsitano, M.; Cristiano,

M.C.; Mancuso, A.; Barone, A.;

Torella, D.; Paolino, D. Lipid-Based Formulations Containing Labrafil M2125-CS: A Deep Investigation on

Nanosystem Stability.

Nanomanufacturing 2022, 2, 41-52.

https://doi.org/10.3390/

nanomanufacturing2010003

Academic Editor: Kyeongsoon Park

Received: 17 December 2021

Accepted: 8 February 2022

Published: 15 February 2022

Publisher's Note: MDPI stays neutral with regard to jurisdictional claims in published maps and institutional affiliations.

Copyright: (C) 2022 by the authors. Licensee MDPI, Basel, Switzerland. This article is an open access article distributed under the terms and conditions of the Creative Commons Attribution (CC BY) license (https:// creativecommons.org/licenses/by/ $4.0 /)$.

\begin{abstract}
Labrafil M2125-CS is a non-ionic surfactant component widely used for improving the solubilization of poor water-soluble drugs and as component of lipid-based nanosystem formulation. The aim of this research work was to evaluate in depth the stability of lipid-based nanosystems when exposed at several experimental conditions, such as temperature- and $\mathrm{pH}$-variations, and during a specific storage process-lyophilization. Dynamic light scattering was the main analysis carried out during this research work for investigating eventual physico-chemical variations of nanosystem properties after different storage phases. We demonstrated that many of prepared formulations were able to maintain almost unchanged mean size and polydispersity index values, resisting acid and basic $\mathrm{pH}$ or high and low temperature, as well as the freeze-drying process. Finally, the results showed that there are no univocal experimental conditions suitable for the storage of all formulation types, but each sample requires customized conditions.
\end{abstract}

Keywords: labrafil M2125-CS; nanosystems; dynamic light scattering; stability studies; lyophilization

\section{Introduction}

The drug delivery systems' approach was developed in order to obtain therapeutic effect and overcome all the limitations of drug administration in free form, such as sideeffects due to nonspecific action, number of administrations, instability of active compounds in physiological conditions, etc. [1,2].

In these attempts, several lipid-based colloidal systems, including a heterogeneous set of nanoformulations, have been realized to obtain a controlled delivery of drugs with different physicochemical features [3]. Several parameters had to be considered for the design of a suitable nanosystem, such as drug solubility, mean size and size distribution of the particles, and colloidal formulation stability.

Considering that one of the main disadvantages in the translation of nanoformulations into clinical practice is its high costs [4] derived from expensive preparation methods and components, and detailed manufacture and quality control, the importance of stability evaluation through the investigation of several factors play an important role, determining preparation process, storage conditions and applications.

Chemical and physical changes in lipid components might modify certain properties, thus leading to different in vivo responses, e.g., particle size can affect cellular uptake [5]. A deeper investigation into physicochemical parameters, also considering the influence of external factors such as temperatures and $\mathrm{pH}$, could prevent instability phenomena such as flocculation, sedimentation, or coagulation [6]. Lyophilization is a widely employed storage method in several fields, as well as a pharmaceutical one, with the advantage to prevent degradation and guarantee optimal starting conditions after sample resuspension. 
In this regard, several critical points need to be considered, such as lipid integrity preserved by cryoprotectants, the presence of different lipids, and physicochemical parameters, thus developing an optimization of the realization process $[7,8]$.

The use of lipid-based formulations, i.e., fatty acid derivatives with various head group moieties, for several drug delivery is already firmly established [9]. Specifically, Labrafil is a non-ionic surfactant composed of a mixture of glycerides and fatty acid esters, acting as solubilizer for poorly soluble molecules [10]. It is mainly used for oral administration and leads to the increase in oral bioavailability of several compounds [11]. Labrafil consists of mono-, di- and triglycerides and PEG-6 (MW 300) mono- and diesters of linoleic (C18:2) acid. The presence of these glycerides also shows antimicrobial activity $[12,13]$. The aim of the work is to explore stability properties of lipid-based formulations, made up of Labrafil M2125-CS, by investigating physicochemical parameters such as mean size, polydispersity index and long-term stability as a function of storage time, temperature, $\mathrm{pH}$, and lyophilization process. The data obtained offer a broader context, setting the stage for further studies.

\section{Materials and Methods}

\subsection{Materials}

Phospholipon $90 \mathrm{G}^{\circledR}\left(\mathrm{PL}-90 \mathrm{G}^{\circledR}\right)$, a purified, deoiled, and granulated soy lecithin with phosphatidylcholine content of at least $90 \%$, was obtained from Natterman Phospholipid GMBH (Köln, Germany) and was used without further purification. Labrafil M2125 was purchased from Gattefossè (Saint-Priest, France). Cellulose membranes Spectra/Por MWCO 50 KDa were obtained from Spectrum Laboratories, Inc. (Eindhoven, The Nether-

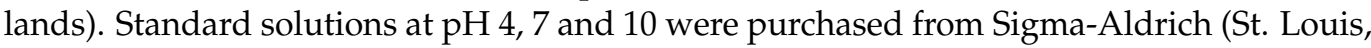
MO, USA). Glucose, trehalose, sucrose, and mannose, used as cryoprotectants, were all purchased from Sigma-Aldrich (Milan, Italy). Deionized double-distilled water (MilliQ) was used throughout the study.

\subsection{Preparation of Labrafil M2125-Based Nanosystems}

To prepare lipid-based formulations, different amounts of PL-90G ${ }^{\circledR}$ and Labrafil M2125-CS were homogenized, according to an easy manufacturing method developed in our laboratory and already used for the preparation of unsaturated fatty acids vesicles [14,15]. The preparation method was slightly modified. In detail, $20 \mathrm{mg}$ of lipid components was suspended in $3 \mathrm{~mL}$ of deionized double-distilled water at room temperature. The samples were submitted to a vigorous process of homogenization by using Ultraturrax ${ }^{\circledR}$ (model T25; IKA ${ }^{\circledR}$ Werke GmbH and Co., Staufen, Germany), alternating one cycle at 15,000 rpm of 15 min with one rest cycle of the same duration and repeating this protocol three times. During homogenization, the samples were immersed in an ice bath to avoid temperature increase, which could modify their physico-chemical features. Then, to remove unreacted compounds and impurities, the systems were purified by dialysis method (cut-off $50 \mathrm{kDa}$ ) for $30 \mathrm{~min}$ in deionized double-distilled water at room temperature [16]. Finally, samples were collected into pyrex glass vials and stored at $+4{ }^{\circ} \mathrm{C}$ until the analysis.

\subsection{Physico-Chemical Characterization of Gained Nanosystems}

The physico-chemical features of nanosystems were assessed by means of dynamic light scattering (DLS), using a Zetasizer Nano ZS apparatus (Malvern Instruments Ltd., Worcestershire, UK) following a 1:20 dilution of samples and applying the third order cumulant correlation function, as reported in previous works [17]. From this analysis, mean sizes and polydispersity indexes of samples were collected and expressed as mean values of three independent experiments \pm standard deviation.

The stability of the formulations was determined firstly by macroscopic examination and then by using a Turbiscan Lab ${ }^{\circledR}$ Expert, equipped with a Turbiscan Lab Cooler. The samples were placed into a cylindrical glass tube and measurements were carried out for $1 \mathrm{~h}$ at $25 \pm 1{ }^{\circ} \mathrm{C}$. During the analysis, the integrated TurbiSoft software 2.0.0.33 (Formulaction, 
L'Union, France) recorded variations of deltabackscattering ( $\triangle \mathrm{BS}$ ) and delta-transmission $(\Delta \mathrm{T})$ profiles and provided a cumulative evaluation of destabilization kinetic of samples through TSI (Turbiscan Stability Index) values [18].

\subsection{Assessment of Storage, $\mathrm{pH}$, and Temperature Influence on Stability}

After a canonic characterization of formulations size and polydispersity index, a deeper investigation into nanostructure stability under different conditions of storage, temperature, and $\mathrm{pH}$ values was assessed. Each of these parameters could affect systems integrity and cause instability phenomena, as aggregation, phase separation or nothomogeneous size in particle distribution. Mean sizes and polydispersity were re-evaluated: (i) after samples storage at $4{ }^{\circ} \mathrm{C}$ for $24 \mathrm{~h}, 1$ week, 2 weeks or 1 month; (ii) analyzing samples at greater temperatures $\left(30,40,50^{\circ} \mathrm{C}\right)$; (iii) incubating samples in standard solutions at different $\mathrm{pH}$ values $(4,7,10)$.

\subsection{Freeze-Drying Studies}

The lyophilizer (VirTis SP scientific sentry 2.0; SP Industries, Warminster, PA, USA) was used to carry out a freeze-drying process. Aliquots $(500 \mu \mathrm{L})$ of each formulation were placed in suitable polypropylene tubes together with four different cryoprotectants (glucose, trehalose, sucrose, and mannose) at two different concentration (5 and 10\% w/v) and frozen in liquid nitrogen for $2 \mathrm{~min}$. Therefore, frozen samples were put in the freezedrying chamber and cryo-dried for $24 \mathrm{~h}$, thanks to equipped vacuum pump (B14 model; Carpanelli S.p.a., Bologna, Italy). After 3 days of storage at room temperature, the obtained lyophilized fine particles were rehydrated and gently shaken. The ability of samples to be resuspended and the physicochemical properties of resulting colloidal dispersions were evaluated by DLS analysis.

\subsection{Statistical Analysis}

The statistical analysis was carried out with a one-way ANOVA test. Bonferroni t-test was used to check the obtained results and the significance levels were fixed at ${ }^{*} p<0.05$ and ${ }^{* *} p<0.001$.

\section{Results and Discussion}

\subsection{Physico-Chemical and Technological Characterization}

The evaluation of the physicochemical features of the nanosystems is a crucial factor to investigate since the mean size and the polydispersity index are fundamental aspects as they strongly influence the biopharmaceutical fate of the formulations. This step acquires much more importance when a new carrier is realized, or a different method is used during the preparation of systems. In this study, a non-ionic surfactant Labrafil M2125-C (LBF) was combined with PL- $90 \mathrm{G}^{\circledR}$ in different molar ratios, according to the procedure described in Section 2.2 for the realization of an innovative system. We obtained six formulations, characterized by specific physico-chemical characteristics, reported in Table 1. Each sample had low PdI values $(\leq 0.3)$, accepted as representing a monodisperse population of colloidal particles [19-21], and mean sizes below $130 \mathrm{~nm}$. The amount of LBF in the mixture determined an effect on sizes as the increase of LBF concentration corresponded to a reduction in the average diameter. Acting like a surfactant, LBF could be responsible for a lipids rearrangement in the structure [22], leading to smaller system dimension (up to about $80 \mathrm{~nm}$ ), but maintaining in any case a suitable polydispersity index. Dynamic Light Scattering profiles of some samples are reported in Figure S1. The impact of LBF in dimensional reduction of dispersion components is an interesting element to take into consideration in the panorama of drug delivery systems, since size could affect some of their properties, such as the release rate of entrapped drugs [23-25]. 
Table 1. Composition and physicochemical features of PL-90G ${ }^{\circledR}$ and Labrafil M2125-based nanosystems. Data are expressed as mean values of three independent experiments \pm standard deviation.

\begin{tabular}{cccc}
\hline & & \multicolumn{1}{c}{$\mathbf{t = 0}$} \\
\hline Samples & $\begin{array}{c}\text { Molar Ratio } \\
\text { PL-90G }^{\circledR} / \mathbf{L B F}\end{array}$ & $\begin{array}{c}\text { Mean Sizes } \\
\mathbf{( n m )}\end{array}$ & PdI $^{\mathbf{1}}$ \\
\hline A & $0.24: 0.76$ & $83 \pm 1$ & $0.15 \pm 0.01$ \\
B & $0.32: 0.68$ & $91 \pm 1$ & $0.28 \pm 0.02$ \\
C & $0.48: 0.52$ & $91 \pm 1$ & $0.10 \pm 0.01$ \\
D & $0.44: 0.56$ & $94 \pm 1$ & $0.18 \pm 0.01$ \\
E & $0.64: 0.36$ & $109 \pm 1$ & $0.09 \pm 0.03$ \\
F & $0.76: 0.24$ & $129 \pm 1$ & $0.16 \pm 0.02$ \\
\hline
\end{tabular}

${ }^{1}$ PdI, polydispersity index.

A macroscopic investigation showed no aggregation phenomena macroscopically visible and no phase separation.

To confirm the stability of these systems, a Turbiscan Lab ${ }^{\circledR}$ Expert instrument was used. This tool provides a non-invasive method of analysis that predicts the long-term stability of solutions or suspensions and provides real-time information on the destabilization process $[26,27]$. Recorded variation of backscattering and transmission profiles of systems, after $1 \mathrm{~h}$ of analysis, are illustrated in Figure 1, where $\Delta \mathrm{BS}$ (panel $\mathrm{A}$ ) and $\Delta \mathrm{T}$ (panel B) profiles are shown as a function of sample height. As shown, both $\Delta \mathrm{BS}$ and $\Delta \mathrm{T}$ values of LBF-based formulations demonstrated that no relevant modifications of signals occurred during analysis and an overlapping of six curves was obtained. Variations in the transmission and/or backscattering profiles of samples within an interval of $\pm 2 \%$ are not considered meaningful of instability [18], thus demonstrating that no sedimentation, aggregation, or phase separation occurred during the analysis. The presence of greater peaks from 0 to $2 \mathrm{~mm}$ of sample height (Figure 1) is not related to instability phenomena of the system but it can be ascribable to the thickness of the bottom of the glass vial [28]. Overall, all the samples are considered stable dispersion systems.

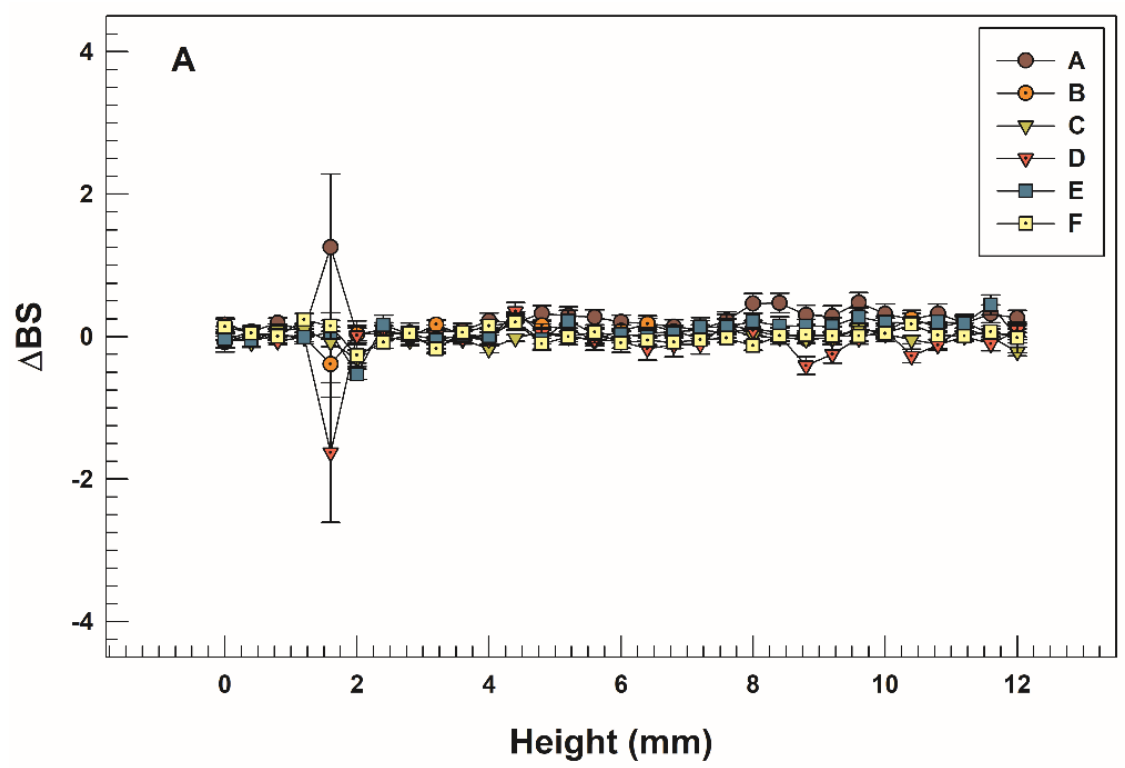

Figure 1. Cont. 


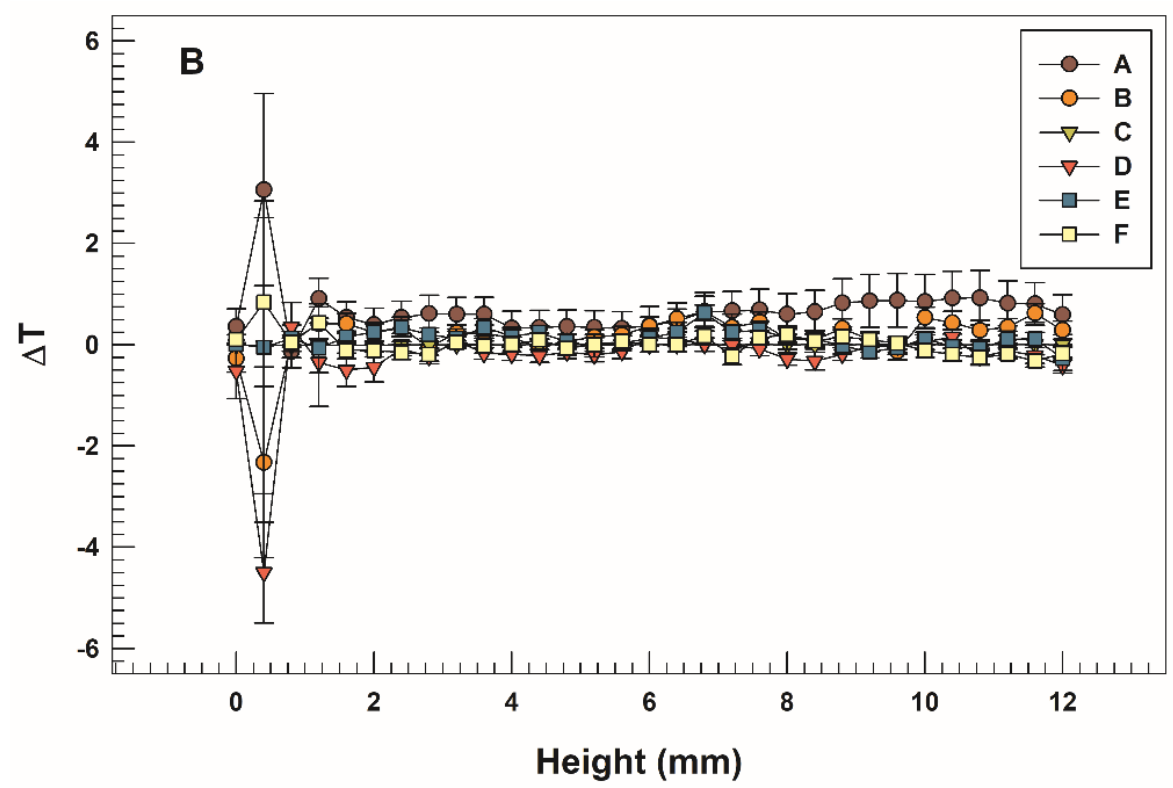

Figure 1. Variation of (A) Backscattering and (B) Transmission profiles of formulations. The analysis was performed at $25 \pm 1{ }^{\circ} \mathrm{C}$ and data are representative of three independent experiments. Results are reported as a function of sample height $(\mathrm{mm})$ and time $(0-1 \mathrm{~h})$.

The long-term stability of investigated formulations was further confirmed by the destabilization kinetic profiles (Turbiscan Stability Index, TSI). The TSI is a relative number that estimates colloidal dispersion stability. High values of the TSI indicate instability and higher probability of phase separation, whereas lower TSI values denote more stability of the system $[29,30]$. Figure 2 shows that all formulations had good and comparable TSI values $(<4)$, confirming the results obtained from previous studies [31].

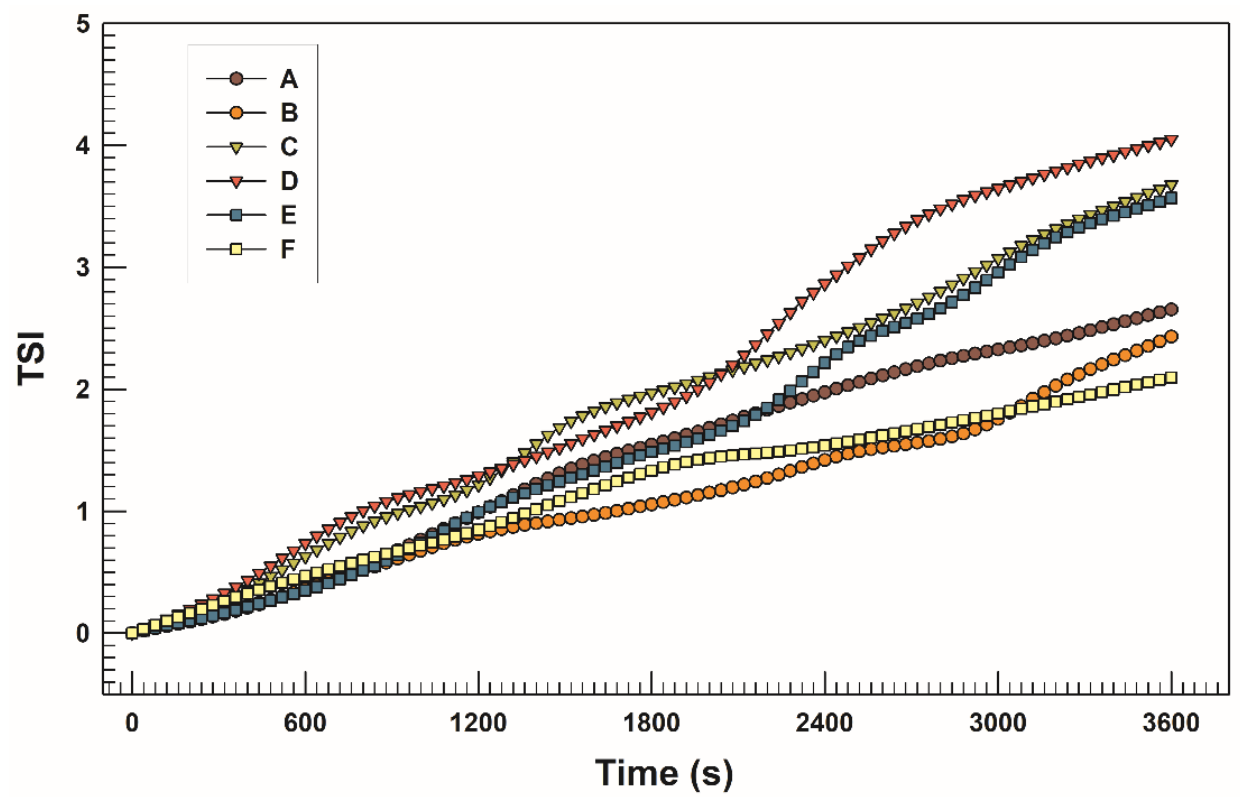

Figure 2. TSI values of formulations obtained by using Turbiscan Lab ${ }^{\circledR}$ Expert and TurbiSoft software. Data are representative of three independent experiments.

\subsection{Storage, $p H$, and Temperature Influence on Stability}

A physico-chemical characterization of newly synthesized systems represents only the first step of a long chain of subsequent detailed investigations. Afterall, a formulation intended for pharmaceutical use must meet requirements that go far beyond proper size and 
stability under conventional conditions. The obtained samples could be perturbed in their properties by thermal stress or by $\mathrm{pH}$ variations, both in the physiological environment and in the production, management, and storage processes. For most commercial applications, it is important that the properties of nano-based delivery systems remain physically stable throughout their shelf life, as much as the achieving of an appropriate chemical stability of active compounds $[32,33]$. To assess the samples' ability to retain a certain stability under conditions of temperature variations, they were stored at $4{ }^{\circ} \mathrm{C}$ for $24 \mathrm{~h}$, 1 week, 2 weeks, and 1 month. After these times, they were re-analyzed by using DLS (Table 2). Samples containing the highest amounts of $\operatorname{LBF}(\mathrm{A}, \mathrm{B}, \mathrm{C})$ showed stable dimensions until 1 month from the preparation day. In details, formulation $\mathrm{A}$, which had minor mean size after the homogenization process (see Table 1), was able to maintain its feature with a very slight increase in mean size values, starting from $83 \mathrm{~nm} \pm 1$ at $\mathrm{t}=0$ until $86 \mathrm{~nm} \pm 1$ (Table 2) after 1 month of storage at $4{ }^{\circ} \mathrm{C}\left({ }^{*} p<0.05\right)$. Formulations $\mathrm{B}$ and $\mathrm{C}$ were dimensionally stable until the end of the investigation; in fact, after 30 days, DLS analysis showed no relevant variations of mean sizes (92 \pm 1 and $107 \pm 1 \mathrm{~nm}$, respectively). When the ratio of LBF to PL-90G decreased, a slight but more detectable increase in the mean diameter of the dispersed droplets occurred, as noted for the D-F formulations. Even after 1 week, sample $\mathrm{D}$ underwent an increase of $\sim 100 \mathrm{~nm}\left({ }^{* *} p<0.001\right)$. The most evident rise in system mean sizes was obtained with formulations $\mathrm{E}$ and F, containing the minor quantity of LBF; at 1 month of storage, DLS analysis could not be carried out, due to the presence of sediments visible to the naked eye on the bottom of the vial. Polydispersity indexes were largely maintained at low values, with a special regard to A, B, and C samples in which PdI even diminished, compared to the initial one. Overall, these results showed that the mean size trend observed in Table 2 was preserved, thus confirming LBF influence on nanostructures and assessing a suitable stability under controlled temperature storage, without any drying process [22].

Table 2. Influence of storage at $4{ }^{\circ} \mathrm{C}$ on samples mean size and PdI as function of time (t). Data are listed as mean values of three independent experiments \pm standard deviation.

\begin{tabular}{|c|c|c|c|c|c|c|c|c|}
\hline \multirow[b]{2}{*}{ Sample } & \multicolumn{2}{|c|}{$t=24 h$} & \multicolumn{2}{|c|}{$t=1$ Week } & \multicolumn{2}{|c|}{$\mathrm{t}=2$ Weeks } & \multicolumn{2}{|c|}{$t=1$ Month } \\
\hline & $\begin{array}{c}\text { Mean Size } \\
(\mathrm{nm})\end{array}$ & PdI & $\begin{array}{l}\text { Mean Size } \\
\text { (nm) }\end{array}$ & PdI & $\begin{array}{l}\text { Mean Size } \\
\text { (nm) }\end{array}$ & PdI & $\begin{array}{c}\text { Mean Size } \\
\text { (nm) }\end{array}$ & PdI \\
\hline A & $84 \pm 1$ & $0.14 \pm 0.02$ & $89 \pm 1$ & $0.12 \pm 0.01$ & $89 \pm 1$ & $0.10 \pm 0.01$ & $86 \pm 1$ & $0.08 \pm 0.02$ \\
\hline B & $84 \pm 1$ & $0.14 \pm 0.01$ & $84 \pm 1$ & $0.14 \pm 0.01$ & $84 \pm 1$ & $0.14 \pm 0.10$ & $92 \pm 1$ & $0.15 \pm 0.01$ \\
\hline $\mathrm{C}$ & $103 \pm 1$ & $0.07 \pm 0.01$ & $107 \pm 1$ & $0.06 \pm 0.01$ & $106 \pm 1$ & $0.06 \pm 0.02$ & $107 \pm 1$ & $0.09 \pm 0.01$ \\
\hline $\mathrm{D}$ & $102 \pm 1$ & $0.18 \pm 0.02$ & $191 \pm 2$ & $0.30 \pm 0.02$ & $199 \pm 1$ & $0.08 \pm 0.01$ & $203 \pm 1$ & $0.03 \pm 0.01$ \\
\hline $\mathrm{E}$ & $148 \pm 1$ & $0.33 \pm 0.01$ & $133 \pm 1$ & $0.18 \pm 0.01$ & $138 \pm 2$ & $0.11 \pm 0.01$ & \#\# & \#\# \\
\hline $\mathrm{F}$ & $153 \pm 1$ & $0.25 \pm 0.01$ & $150 \pm 2$ & $0.20 \pm 0.01$ & $190 \pm 2$ & $0.18 \pm 0.01$ & \#\# & \#\# \\
\hline
\end{tabular}

\#\# Sample not suitable for analysis.

Further stability investigation as a function of temperature was performed, evaluating the samples' properties during heating with DLS apparatus. The rise in temperature can affect system stability and aggregation phenomena can be generated by the increase in the degree of disorder and collisions between the particles forming the colloid or by the physical degradation of components that risk losing their function and structure. The effect of heat treatment on the mean sizes was studied by exposing freshly formed formulations to constant temperature values of 30,40 , and $50{ }^{\circ} \mathrm{C}$ during dynamic light scattering analysis.

The results showed that there were no relevant differences in the mean sizes in any of the studied samples (Table 3). The first four samples (A-D) were not affected by heating at all, since their physicochemical characteristics were not distorted at any temperature used. 
Table 3. Influence of temperature (T) on the samples' mean size and PdI. Data are listed as mean values of three independent experiments \pm standard deviation.

\begin{tabular}{cccccccc}
\hline & \multicolumn{2}{c}{$\mathbf{T}=\mathbf{3 0}{ }^{\circ} \mathbf{C}$} & \multicolumn{2}{c}{$\mathbf{T}=\mathbf{4 0}{ }^{\circ} \mathbf{C}$} & \multicolumn{2}{c}{$\mathbf{T}{ }^{\circ} \mathbf{C}$} \\
\hline Sample & Mean Size $(\mathbf{n m})$ & PdI & Mean Size (nm) & PdI & Mean Size (nm) & PdI \\
\hline A & $90 \pm 1$ & $0.14 \pm 0.01$ & $91 \pm 3$ & $0.12 \pm 0.01$ & $91 \pm 3$ & $0.13 \pm 0.01$ \\
\hline B & $90 \pm 1$ & $0.26 \pm 0.01$ & $93 \pm 5$ & $0.27 \pm 0.01$ & $94 \pm 8$ & $0.27 \pm 0.01$ \\
\hline C & $85 \pm 2$ & $0.13 \pm 0.01$ & $82 \pm 7$ & $0.09 \pm 0.01$ & $89 \pm 1$ & $0.07 \pm 0.02$ \\
\hline D & $87 \pm 1$ & $0.09 \pm 0.01$ & $89 \pm 6$ & $0.10 \pm 0.01$ & $92 \pm 1$ & $0.10 \pm 0.01$ \\
\hline E & $140 \pm 1$ & $0.29 \pm 0.01$ & $144 \pm 4$ & $0.24 \pm 0.01$ & $142 \pm 3$ & $0.24 \pm 0.03$ \\
\hline F & $153 \pm 4$ & $0.14 \pm 0.01$ & $168 \pm 9$ & $0.24 \pm 0.01$ & $175 \pm 6$ & $0.23 \pm 0.02$ \\
\hline
\end{tabular}

On the other hand, some formulations ( $\mathrm{E}$ and $\mathrm{F}$ ) were mostly influenced by these conditions. In detail, at $30^{\circ} \mathrm{C}$, formulation $\mathrm{E}$ increased their size to above $30 \mathrm{~nm}(* * p<0.001)$ but retained a PdI value lower than 0.3; on increasing the heating temperature, both evaluated parameters remained constant.

On the contrary, formulation $\mathrm{F}$, which was previously considered unstable after longterm storage, initially showed a reduction in mean sizes $\left(153 \pm 4\right.$ at $30{ }^{\circ} \mathrm{C}$ - $\left.{ }^{* *} p<0.001\right)$ that increased again linearly at a higher temperature.

Furthermore, in this case, the samples with higher content of non-ionic surfactant seemed to represent the best formulations in terms of stability. This stability might be ascribed to the sufficient presence of repulsive interactions between the components of the dispersed system, which prevent aggregation or creaming events, assuring an optimum homogeneity of samples. In Figure 3, the results of mean size and PdI were reported as a graph and as a function of temperature, to show better the related influences.

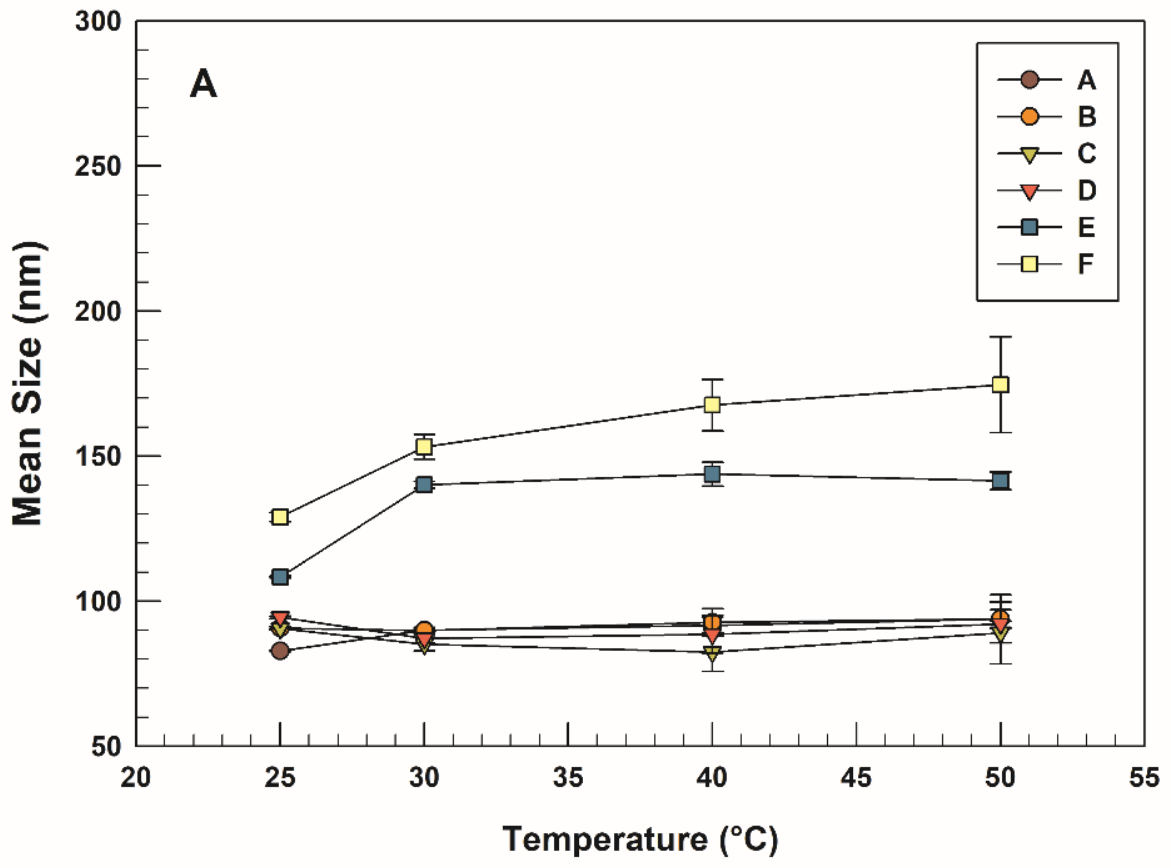

Figure 3. Cont. 


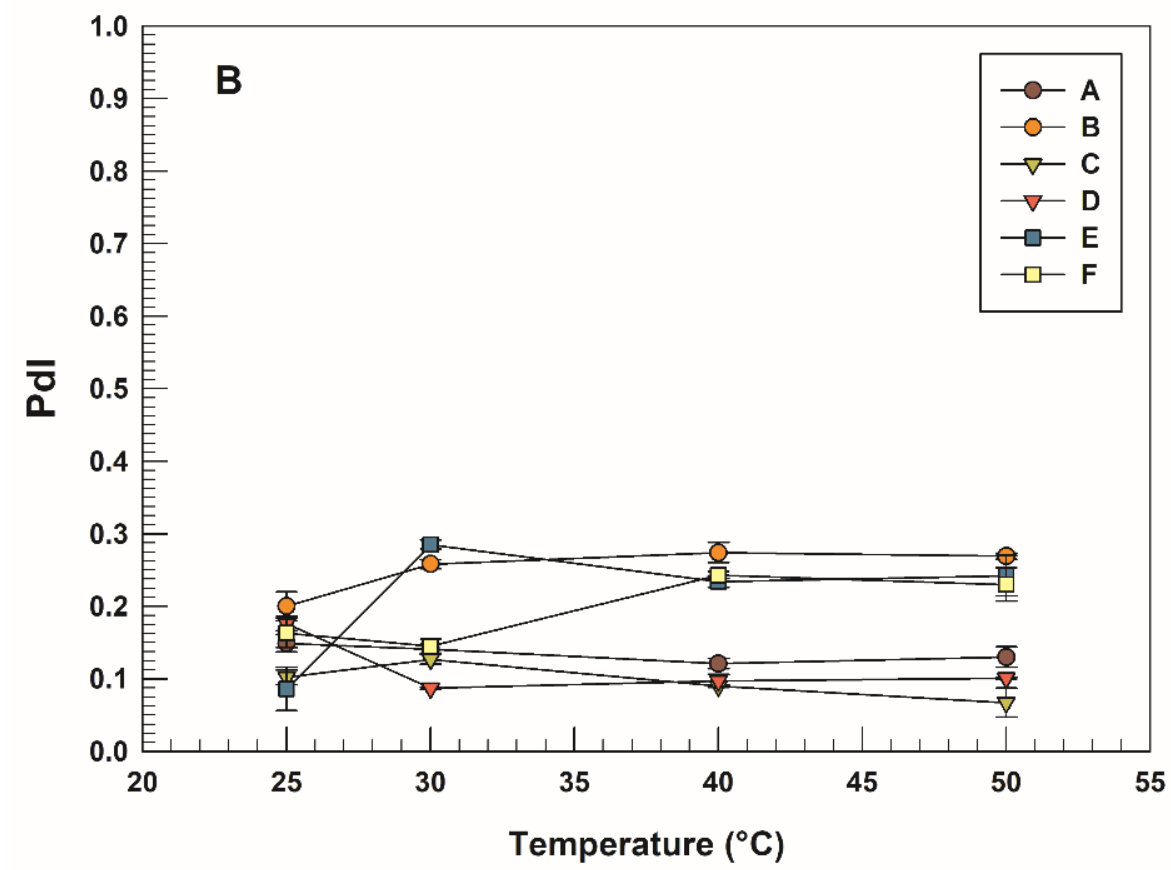

Figure 3. Stability trends of formulations expressed as mean sizes (A) and PdI (B) variations as function of temperature. Data are listed as mean values of three independent experiments \pm standard deviation.

Examining the effect of $\mathrm{pH}$ on changes in physicochemical parameters is an issue of fundamental importance due to its direct correlation with the applicability of any pharmaceutical form.

In fact, it influences various stages in the fate of drug delivery systems administration, starting from their quantity present in the absorption site and dissolution of the pharmaceutical form to entrapment in biological membranes.

From the test of stability at different $\mathrm{pH}$ values, a different situation emerged, thus not confirming the trend previously observed during temperature changes.

In acid condition $(\mathrm{pH}=4)$, all the samples had slightly increased dimensions, independently from the LBF/PL- $90 \mathrm{G}^{\circledR}$ molar ratio; on the contrary, the DLS analysis showed that the mean size trends occurring in standard condition were maintained also at $\mathrm{pH} 7$ and 10, as shown in Table 4. The PdI of each formulation was maintained under 0.3 value, indicating a narrow size distribution.

Table 4. Influence of $\mathrm{pH}$ variation on samples mean size and PdI. Data are listed as mean values of three independent experiments \pm standard deviation.

\begin{tabular}{ccccccc}
\hline & \multicolumn{2}{c}{$\mathrm{pH}=\mathbf{4}$} & \multicolumn{2}{c}{$\mathrm{pH}=\mathbf{7}$} & \multicolumn{2}{c}{$\mathrm{pH}=\mathbf{1 0}$} \\
\hline Sample & Mean Size $(\mathbf{n m})$ & PdI & Mean Size (nm) & PdI & Mean Size (nm) & PdI \\
\hline A & $131 \pm 8$ & $0.06 \pm 0.02$ & $87 \pm 1$ & $0.17 \pm 0.01$ & $92 \pm 1$ & $0.22 \pm 0.01$ \\
\hline B & $130 \pm 8$ & $0.08 \pm 0.01$ & $94 \pm 1$ & $0.11 \pm 0.01$ & $103 \pm 1$ & $0.17 \pm 0.01$ \\
\hline C & $130 \pm 7$ & $0.09 \pm 0.02$ & $96 \pm 1$ & $0.11 \pm 0.01$ & $113 \pm 1$ & $0.16 \pm 0.02$ \\
\hline D & $131 \pm 6$ & $0.05 \pm 0.01$ & $107 \pm 1$ & $0.10 \pm 0.01$ & $116 \pm 1$ & $0.13 \pm 0.01$ \\
\hline E & $128 \pm 3$ & $0.16 \pm 0.01$ & $123 \pm 1$ & $0.24 \pm 0.01$ & $131 \pm 2$ & $0.23 \pm 0.02$ \\
\hline F & $146 \pm 1$ & $0.13 \pm 0.02$ & $155 \pm 1$ & $0.26 \pm 0.01$ & $164 \pm 1$ & $0.21 \pm 0.01$ \\
\hline
\end{tabular}


According to our results, it is possible to affirm that these systems do not undergo breakage if exposed to different $\mathrm{pH}$ conditions; therefore, they are promising for different applications in the pharmaceutical and cosmetic fields.

\subsection{Freeze-Drying Studies}

Lyophilization, also known as freeze-drying, is defined as the industrial or laboratory process that removes big amounts of water from the systems by sublimation under vacuum, at low pressure, and leads to anhydrous product [34].

This method is essential to eliminate free water in the system which could be responsible for microbial growth, drug leakage, and hydrolysis of phospholipids to free fatty acids, decreasing therapeutic efficiency or generating instability phenomena [35,36].

All these events could reduce or impact the final product's shelf life. Despite the previous studies demonstrating that our systems maintained their physico-chemical characteristics up to one month after storage at $4{ }^{\circ} \mathrm{C}$, freeze-drying studies were carried out to evaluate the applicability of the method to ensure further long-term storage and stability.

It is well known that, during the freezing step, the formation of solid amorphous glass (vitrification) between colloidal particles dramatically affects the quality of the product dried by the sublimation process [37].

This damage can be avoided by adding cryoprotectants and applying a fast freezing [38]. Glucose, trehalose, mannose, and sucrose were chosen as mono- and disaccharides to be added in two different concentrations ( 5 and 10\%) to the samples before starting the lyophilization [39].

At the end of the lyophilization process, the obtained dried powders were then gently rehydrated, preventing the disruption of the porous structure caused by rapid addition of water [40].

A DLS analysis was then performed to evaluate physicochemical parameters of the resuspended formulations.

In Table 5, mean size and PdI values are reported for each formulation and each amount of used cryoprotectants.

After rehydration, some samples were not found suitable for analysis and they presented aggregates and unstable structures, confirmed by mean size values that exceeded instrument calibration (>1000 $\mathrm{nm})$.

Physicochemical features of formulations D and F were the best as mean size and PdI were retained at values of $<300 \mathrm{~nm}$ and $<0.3$, respectively. Formulations $\mathrm{A}$ and $\mathrm{B}$, which previously maintained the most appropriate stability parameters, exhibited an unexpected behavior after lyophilization, showing an increase in PDI values. From results obtained from the freeze-drying process using different cryoprotectants, an interesting evidence emerged: one mono- or di-saccharide can ensure the best but also the worst results for two different formulations. For example, sucrose $(5 \% w / v)$ provided one of the best size parameters for obtaining sample F powder (Figure S2), while the same concentration made formulation A, B, C, and E unsuitable for resuspension, as macroscopical aggregates were still visible after shaking. These findings are probably related to the different compositions of the systems, which need different cryoprotectants to obtain a stable dried product and their complete dissolution without presenting any drastic alteration in properties.

Although not all samples were suitable for the freeze-drying process, all formulations can be stored for a long time in different ways. In fact, the same samples (A and B) that did not have suitable size and PDI properties to undergo lyophilization, previously reported great long-term stability in storage conditions at $4{ }^{\circ} \mathrm{C}$. On the contrary, the formulations that underwent greater dimensional and PDI variations when stored at $4{ }^{\circ} \mathrm{C}$, turned out to be suitable for the vacuum cryo-drying process.

Altogether, this outcome is highly positive as all systems have their own method of conservation. 
Table 5. Mean size and PdI of six formulations resuspended in water after lyophilization with different cryoprotectants. Data are listed as mean values of three independent experiments \pm standard deviation.

\begin{tabular}{|c|c|c|c|}
\hline Sample & Cryoprotectant $(\% w / v)$ & Mean Size (nm) & PdI \\
\hline \multirow{8}{*}{$\mathrm{A}$} & Glucose 5\% & $71 \pm 14$ & $0.56 \pm 0.06$ \\
\hline & Glucose $10 \%$ & $178 \pm 6$ & $0.41 \pm 0.06$ \\
\hline & Trehalose 5\% & $238 \pm 7$ & $0.78 \pm 0.08$ \\
\hline & Trehalose $10 \%$ & $357 \pm 28$ & $0.65 \pm 0.03$ \\
\hline & Mannose 5\% & $170 \pm 6$ & $0.46 \pm 0.06$ \\
\hline & Mannose $10 \%$ & $400 \pm 14$ & $0.58 \pm 0.06$ \\
\hline & Sucrose $5 \%$ & \# & $0.96 \pm 0.01$ \\
\hline & Sucrose $10 \%$ & $368 \pm 9$ & $0.54 \pm 0.03$ \\
\hline \multirow{8}{*}{ B } & Glucose 5\% & $112 \pm 22$ & $0.34 \pm 0.02$ \\
\hline & Glucose $10 \%$ & $139 \pm 18$ & $0.59 \pm 0.13$ \\
\hline & Trehalose $5 \%$ & $383 \pm 50$ & $0.77 \pm 0.08$ \\
\hline & Trehalose $10 \%$ & $215 \pm 5$ & $0.38 \pm 0.01$ \\
\hline & Mannose 5\% & \# & $0.49 \pm 0.08$ \\
\hline & Mannose $10 \%$ & $436 \pm 21$ & $0.63 \pm 0.07$ \\
\hline & Sucrose $5 \%$ & \# & $0.79 \pm 0.06$ \\
\hline & Sucrose $10 \%$ & $241 \pm 4$ & $0.32 \pm 0.02$ \\
\hline \multirow{8}{*}{ C } & Glucose $5 \%$ & $72 \pm 50$ & $0.41 \pm 0.02$ \\
\hline & Glucose $10 \%$ & $225 \pm 39$ & $0.15 \pm 0.02$ \\
\hline & Trehalose 5\% & \# & $0.57 \pm 0.04$ \\
\hline & Trehalose $10 \%$ & $271 \pm 25$ & $0.58 \pm 0.14$ \\
\hline & Mannose 5\% & \# & $0.68 \pm 0.08$ \\
\hline & Mannose $10 \%$ & \# & $0.77 \pm 0.01$ \\
\hline & Sucrose 5\% & $\#$ & $0.88 \pm 0.05$ \\
\hline & Sucrose $10 \%$ & $308 \pm 13$ & $0.50 \pm 0.03$ \\
\hline \multirow{8}{*}{$\mathrm{D}$} & Glucose 5\% & $209 \pm 6$ & $0.17 \pm 0.03$ \\
\hline & Glucose $10 \%$ & $214 \pm 4$ & $0.21 \pm 0.01$ \\
\hline & Trehalose 5\% & $124 \pm 1$ & $0.26 \pm 0.02$ \\
\hline & Trehalose $10 \%$ & $155 \pm 1$ & $0.25 \pm 0.01$ \\
\hline & Mannose 5\% & $501 \pm 13$ & $0.66 \pm 0.02$ \\
\hline & Mannose $10 \%$ & $218 \pm 3$ & $0.50 \pm 0.01$ \\
\hline & Sucrose $5 \%$ & $304 \pm 8$ & $0.67 \pm 0.05$ \\
\hline & Sucrose $10 \%$ & \# & $0.43 \pm 0.08$ \\
\hline \multirow{8}{*}{ E } & Glucose 5\% & $82 \pm 15$ & $0.56 \pm 0.01$ \\
\hline & Glucose $10 \%$ & $100 \pm 24$ & $0.59 \pm 0.04$ \\
\hline & Trehalose 5\% & $213 \pm 3$ & $0.52 \pm 0.06$ \\
\hline & Trehalose $10 \%$ & $239 \pm 2$ & $0.24 \pm 0.01$ \\
\hline & Mannose 5\% & $326 \pm 4$ & $0.43 \pm 0.01$ \\
\hline & Mannose $10 \%$ & $203 \pm 2$ & $0.50 \pm 0.01$ \\
\hline & Sucrose 5\% & \# & $0.57 \pm 0.01$ \\
\hline & Sucrose $10 \%$ & $\#$ & $0.72 \pm 0.06$ \\
\hline \multirow{8}{*}{$\mathrm{F}$} & Glucose $5 \%$ & $350 \pm 7$ & $0.40 \pm 0.01$ \\
\hline & Glucose $10 \%$ & $148 \pm 36$ & $0.96 \pm 0.08$ \\
\hline & Trehalose 5\% & $148 \pm 3$ & $0.43 \pm 0.04$ \\
\hline & Trehalose $10 \%$ & $152 \pm 1$ & $0.29 \pm 0.01$ \\
\hline & Mannose 5\% & $152 \pm 2$ & $0.18 \pm 0.02$ \\
\hline & Mannose $10 \%$ & \# & $0.58 \pm 0.02$ \\
\hline & Sucrose 5\% & $181 \pm 1$ & $0.16 \pm 0.03$ \\
\hline & Sucrose $10 \%$ & $216 \pm 2$ & $0.18 \pm 0.02$ \\
\hline
\end{tabular}

\# Exceeds calibration.

\section{Conclusions}

The present study described the physico-chemical features of lipid-based nanosystems containing Labrafil 2125-CS and PL-90G ${ }^{\circledR}$, proposing a new and low-cost method of preparation, based on an easy homogenization process. A deep investigation on several 
formulations was performed, evaluating physico-chemical features both in standard conditions of temperature and under specific stress, such as $\mathrm{pH}$ and temperature variations and as function of storage time. The results highlighted that these lipid-based formulations were able to maintain suitable mean size, on a nanometric scale, and a narrow size distribution, independently of the experimental conditions. Furthermore, this large pool of results has shown that there are no univocal experimental conditions suitable for the storage of all formulation types, but each sample requires customized conditions. In any case, the results are encouraging and suggest the use of these nanosystems for applications as suitable carriers for several administrations.

Supplementary Materials: The following supporting information can be downloaded at: https: / / www.mdpi.com/article/10.3390/nanomanufacturing2010003/s1, Figure S1: Size distribution by intensity (left) and raw correlation data (right) of samples A, C, and F at t0. The name of each panel is related to sample's letter. Data showed are representative of three independent measurements. The plots not visible in the graph but present in the legend were overlayed; Figure S2: Size distribution by intensity (left) and raw correlation data (right) of sample F after freeze-drying process with Mannose $5 \%$ (panel 1) and Sucrose 5\% (panel 2). Data showed are representative of three independent measurements. The plots not visible in the graph but present in legend were overlayed.

Author Contributions: Conceptualization, M.C.C. and D.P.; investigation, M.C.C. and M.T.; data curation, A.M. and A.B.; writing-original draft preparation, A.M. and M.T.; writing—review and editing, M.C.C. and A.B.; supervision, D.T. and D.P. All authors have read and agreed to the published version of the manuscript.

Funding: This research received no external funding.

Institutional Review Board Statement: Not applicable.

Informed Consent Statement: Not applicable.

Data Availability Statement: The data presented in this study are available on request from the corresponding author.

Conflicts of Interest: The authors declare no conflict of interest.

\section{References}

1. Allen, T.M.; Cullis, P.R. Drug Delivery Systems: Entering the Mainstream. Science 2004, 303, 1818-1822. [CrossRef] [PubMed]

2. Puglia, C.; Lauro, M.R.; Tirendi, G.G.; Fassari, G.E.; Carbone, C.; Bonina, F.; Puglisi, G. Modern drug delivery strategies applied to natural active compounds. Expert Opin. Drug Deliv. 2016, 14, 755-768. [CrossRef] [PubMed]

3. Shrestha, H.; Bala, R.; Arora, S. Lipid-Based Drug Delivery Systems. J. Pharm. 2014, 2014, 801820. [CrossRef] [PubMed]

4. Anselmo, A.C.; Mitragotri, S. An overview of clinical and commercial impact of drug delivery systems. J. Control. Release 2014, 190, 15-28. [CrossRef]

5. He, C.; Hu, Y.; Yin, L.; Tang, C.; Yin, C. Effects of particle size and surface charge on cellular uptake and biodistribution of polymeric nanoparticles. Biomaterials 2010, 31, 3657-3666. [CrossRef]

6. Heurtault, B.; Saulnier, P.; Pech, B.; Proust, J.-E.; Benoit, J.-P. Physicochemical stability of colloidal lipid particles. Biomaterials 2003, 24, 4283-4300. [CrossRef]

7. Susa, F.; Bucca, G.; Limongi, T.; Cauda, V.; Pisano, R. Enhancing the preservation of liposomes: The role of cryoprotectants, lipid formulations and freezing approaches. Cryobiology 2021, 98, 46-56. [CrossRef]

8. Chen, C.; Han, D.; Cai, C.; Tang, X. An overview of liposome lyophilization and its future potential. J. Control. Release 2010, 142, 299-311. [CrossRef]

9. Delongeas, J.-L.; de Conchard, G.V.; Beamonte, A.; Bertheux, H.; Spire, C.; Maisonneuve, C.; Becourt-Lhote, N.; Goldfain-Blanc, F.; Claude, N. Assessment of Labrasol ${ }^{\circledR} /$ Labrafi $^{\circledR} /$ Transcutol $^{\circledR}(4 / 4 / 2, v / v / v)$ as a non-clinical vehicle for poorly water-soluble compounds after 4-week oral toxicity study in Wistar rats. Regul. Toxicol. Pharmacol. 2010, 57, 284-290. [CrossRef]

10. Segale, L.; Giovannelli, L.; Bonda, A.F.; Pattarino, F.; Rinaldi, M. Effect of self-emulsifying phase composition on the characteristics of venlafaxine loaded alginate beads. J. Drug Deliv. Sci. Technol. 2020, 55, 101483. [CrossRef]

11. Larsen, A.; Holm, R.; Pedersen, M.L.; Müllertz, A. Lipid-based Formulations for Danazol Containing a Digestible Surfactant, Labrafil M2125CS: In Vivo Bioavailability and Dynamic In Vitro Lipolysis. Pharm. Res. 2008, 25, 2769-2777. [CrossRef] [PubMed]

12. Tran, L.T.C.; Gueutin, C.; Frebourg, G.; Burucoa, C.; Faivre, V. Erythromycin encapsulation in nanoemulsion-based delivery systems for treatment of Helicobacter pylori infection: Protection and synergy. Biochem. Biophys. Res. Commun. 2017, 493, 146-151. [CrossRef] [PubMed] 
13. Bergsson, G.; Steingrímsson, Ó.; Thormar, H. Bactericidal effects of fatty acids and monoglycerides on Helicobacter pylori. Int. J. Antimicrob. Agents 2002, 20, 258-262. [CrossRef]

14. Cristiano, M.; Froiio, F.; Mancuso, A.; Cosco, D.; Dini, L.; Di Marzio, L.; Fresta, M.; Paolino, D. Oleuropein-Laded Ufasomes Improve the Nutraceutical Efficacy. Nanomaterials 2021, 11, 105. [CrossRef] [PubMed]

15. Cristiano, M.; Mancuso, A.; Fresta, M.; Torella, D.; De Gaetano, F.; Ventura, C.; Paolino, D. Topical Unsaturated Fatty Acid Vesicles Improve Antioxidant Activity of Ammonium Glycyrrhizinate. Pharmaceutics 2021, 13, 548. [CrossRef] [PubMed]

16. Zhang, Y.-T.; Feng, N.-P.; Shen, L.-N.; Zhao, J.-H. Evaluation of psoralen ethosomes for topical delivery in rats by using in vivo microdialysis. Int. J. Nanomed. 2014, 9, 669-678. [CrossRef]

17. Cristiano, M.C.; Froiio, F.; Mancuso, A.; De Gaetano, F.; Ventura, C.A.; Fresta, M.; Paolino, D. The Rheolaser Master ${ }^{\mathrm{TM}}$ and Kinexus Rotational Rheometer ${ }^{\circledR}$ to Evaluate the Influence of Topical Drug Delivery Systems on Rheological Features of Topical Poloxamer Gel. Molecules 2020, 25, 1979. [CrossRef]

18. Celia, C.; Locatelli, M.; Cilurzo, F.; Cosco, D.; Gentile, E.; Scalise, D.; Carafa, M.; Ventura, C.A.; Fleury, M.; Tisserand, C.; et al. Long Term Stability Evaluation of Prostacyclin Released from Biomedical Device through Turbiscan Lab Expert. Med. Chem. 2015, 11,391-399. [CrossRef]

19. Du, Z.; Munye, M.M.; Tagalakis, A.D.; Manunta, M.; Hart, S.L. The Role of the Helper Lipid on the DNA Transfection Efficiency of Lipopolyplex Formulations. Sci. Rep. 2014, 4, 7107. [CrossRef]

20. Vanaja, K.; Wahl, M.; Bukarica, L.; Heinle, H. Liposomes as carriers of the lipid soluble antioxidant resveratrol: Evaluation of amelioration of oxidative stress by additional antioxidant vitamin. Life Sci. 2013, 93, 917-923. [CrossRef]

21. Li, J.; Shin, G.H.; Chen, X.; Park, H.J. Modified curcumin with hyaluronic acid: Combination of pro-drug and nano-micelle strategy to address the curcumin challenge. Food Res. Int. 2015, 69, 202-208. [CrossRef]

22. Edwards, K.; Almgren, M. Surfactant-induced leakage and structural change of lecithin vesicles: Effect of surfactant headgroup size. Langmuir 1992, 8, 824-832. [CrossRef]

23. Cole, M.L.; Whateley, T.L. Release rate profiles of theophylline and insulin from stable multiple w/o/w emulsions. J. Control. Release 1997, 49, 51-58. [CrossRef]

24. Kukizaki, M.; Goto, M. Preparation and evaluation of uniformly sized solid lipid microcapsules using membrane emulsification. Colloids Surfaces A Physicochem. Eng. Asp. 2007, 293, 87-94. [CrossRef]

25. Jorgensen, L.; Moeller, E.; van de Weert, M.; Nielsen, H.; Frokjaer, S. Preparing and evaluating delivery systems for proteins. Eur. J. Pharm. Sci. 2006, 29, 174-182. [CrossRef] [PubMed]

26. Celia, C.; Trapasso, E.; Cosco, D.; Paolino, D.; Fresta, M. Turbiscan Lab ${ }^{\circledR}$ Expert analysis of the stability of ethosomes ${ }^{\circledR}$ and ultradeformable liposomes containing a bilayer fluidizing agent. Colloids Surf. B Biointerfaces 2009, 72, 155-160. [CrossRef] [PubMed]

27. Liu, J.; Huang, X.-F.; Lu, L.-J.; Li, M.-X.; Xu, J.-C.; Deng, H.-P. Turbiscan Lab ${ }^{\circledR}$ Expert analysis of the biological demulsification of a water-in-oil emulsion by two biodemulsifiers. J. Hazard. Mater. 2011, 190, 214-221. [CrossRef]

28. Mengual, O.; Meunier, G.; Cayré, I.; Puech, K.; Snabre, P. TURBISCAN MA 2000: Multiple light scattering measurement for concentrated emulsion and suspension instability analysis. Talanta 1999, 50, 445-456. [CrossRef]

29. Kaombe, D.D.; Lenes, M.; Toven, K.; Glomm, W.R. Turbiscan as a Tool for Studying the Phase Separation Tendency of Pyrolysis Oil. Energy Fuels 2013, 27, 1446-1452. [CrossRef]

30. Qi, X.; Dong, Y.; Wang, H.; Wang, C.; Li, F. Application of Turbiscan in the homoaggregation and heteroaggregation of copper nanoparticles. Colloids Surfaces A Physicochem. Eng. Asp. 2017, 535, 96-104. [CrossRef]

31. Cristiano, M.C.; Froiio, F.; Mancuso, A.; Iannone, M.; Fresta, M.; Fiorito, S.; Celia, C.; Paolino, D. In vitro and in vivo transepidermal water loss evaluation following topical drug delivery systems application for pharmaceutical analysis. J. Pharm. Biomed. Anal. 2020, 186, 113295. [CrossRef] [PubMed]

32. Chang, Y.; McClements, D.J. Optimization of Orange Oil Nanoemulsion Formation by Isothermal Low-Energy Methods: Influence of the Oil Phase, Surfactant, and Temperature. J. Agric. Food Chem. 2014, 62, 2306-2312. [CrossRef] [PubMed]

33. Sagalowicz, L.; Leser, M.E. Delivery systems for liquid food products. Curr. Opin. Colloid Interface Sci. 2010, 15, 61-72. [CrossRef]

34. Franks, F. Freeze-drying of bioproducts: Putting principles into practice. Eur. J. Pharm. Biopharm. 1998, 45, 221-229. [CrossRef]

35. Abdelwahed, W.; Degobert, G.; Stainmesse, S.; Fessi, H. Freeze-drying of nanoparticles: Formulation, process and storage considerations. Adv. Drug Deliv. Rev. 2006, 58, 1688-1713. [CrossRef] [PubMed]

36. do Vale Morais, A.R.; do Nascimento Alencar, É.; Júnior, F.H.X.; De Oliveira, C.M.; Marcelino, H.R.; Barratt, G.; Fessi, H.; Elaissari, A. Freeze-drying of emulsified systems: A review. Int. J. Pharm. 2016, 503, 102-114. [CrossRef]

37. Beirowski, J.; Inghelbrecht, S.; Arien, A.; Gieseler, H. Freeze drying of nanosuspensions, 2: The role of the critical formulation temperature on stability of drug nanosuspensions and its practical implication on process design. J. Pharm. Sci. 2011, 100, 4471-4481. [CrossRef]

38. Fonte, P.; Reis, S.; Sarmento, B. Facts and evidences on the lyophilization of polymeric nanoparticles for drug delivery. J. Control. Release 2016, 225, 75-86. [CrossRef]

39. Zhang, L.; Liu, L.; Qian, Y.; Chen, Y. The effects of cryoprotectants on the freeze-drying of ibuprofen-loaded solid lipid microparticles (SLM). Eur. J. Pharm. Biopharm. 2008, 69, 750-759. [CrossRef]

40. Schaffazick, S.R.; Pohlmann, A.R.; Dalla-Costa, T.; Guterres, S.S. Freeze-drying polymeric colloidal suspensions: Nanocapsules, nanospheres and nanodispersion. A comparative study. Eur. J. Pharm. Biopharm. 2003, 56, 501-505. [CrossRef] 